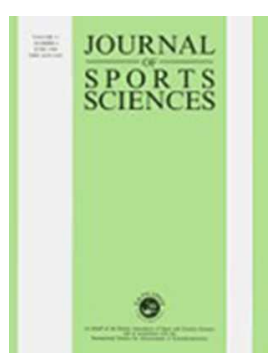

\title{
Relative Age Effect: Implications for Effective Practice
}

\begin{tabular}{|r|l|}
\hline Journal: & Journal of Sports Sciences \\
\hline Manuscript ID: & RJSP-2014-1129.R1 \\
\hline Manuscript Type: & Original Manuscript \\
\hline Keywords: & $\begin{array}{l}\text { Effective talent development, Relative age effect, Reverse relative age } \\
\text { effect }\end{array}$ \\
\hline \multicolumn{3}{|c}{} \\
\hline \\
SCHOLARONE \\
Manuscripts
\end{tabular}




\begin{abstract}
Physical and psychological differences related to birthdate amongst athletes of the same selection year have been characterized as the 'relative age effects' (RAEs). RAEs have been identified in a variety of sports both at youth and adult level and are linked with dropout of athletes and a reduction of the talent pool. This study examined the existence, mechanisms and possible solutions to RAEs using qualitative methodology. Seven experts in the field of talent identification and development were interviewed. Inductive analysis of the data showed while there was mixed evidence for the existence of RAEs across sports, the eradication of RAEs was attributed to controllable features of the development environment. The factors reported included the structure of 'categories' used to group athletes within the sport (e.g. age, weight, size, skills), recognition and prioritization of long term development over 'short term win focus'. Education of relevant parties (e.g. coaches, scouts, clubs) about RAEs and the nature of 'talent' within a long term context was suggested, along with careful consideration of the structure of the development environment (e.g. delayed selection, provision for late developers, focus on skills not results, use of challenge). Implications for research and practice are discussed.
\end{abstract}

Word count of the manuscript: 4.774 words 


\section{Introduction}

Young athletes from the same selection year can be older in comparison to their teammates by up to 12 months, with potentially even greater maturational differences. This can lead to significant cognitive, physical and emotional differences amongst athletes within the same 'competitive' age category (Cobley, Baker, Wattie \& McKenna, 2009a). In turn, these differences (termed relative age effects - RAEs) may result in performance advantages for athletes born at certain times in the selection year. For example, the most commonly reported RAE is that 'older athletes' tend to be more prevalent in strength-based sports. However, research has also shown that relatively 'younger athletes' have performance advantages in 'rotational or gymnastic' type sports (Maffulli, King, \& Helms, 1994). This is sometimes referred to as a 'reverse relative age effect'. Therefore, for some sports it is an advantage to mature later than your teammates and in others earlier.

These effects have been identified in a variety of sports whereby the proportion of birth dates of the athletes that are selected is significantly skewed towards one end of the selection year (Cobley, Baker, Wattie \& McKenna, 2009b; Musch \& Grondin, 2001; Till et al., 2010). RAEs are more likely to occur in physically demanding sports (Baxter-Jones, 1995) where athletes born early in the selection year have a physical advantage. RAEs have been reported in a variety of sports such as football in youth level (Brewer, Balsom, \& Davis, 1995; Jimenez \& Pain, 2008; van den Honert, 2012) and adult level in Belgium, Netherlands, France (Verhulst, 1992), Germany (Bäumler, 1998), Brazil, Australia and Japan (Musch \& Hay, 1999). Additionally, RAEs have been found in ice hockey across Canada in NHL (Barnsley, Thompson, \& Barnsley, 1985; Barnsley \& Thompson, 1988; Boucher \& Halliwell, 1991; Boucher \& Mutimer, 1994), in baseball (Grondin \& 
Joren, 2000), tennis (Bäumler, 1998; Edgar \& O’ Donoghue, 2005), basketball (Delorme \& Raspaud, 2009), netball and cricket (O' Donoghue, Edgar, \& McLaughlin, 2004).

In swimming (Baxter-Jones, 1995) and volleyball (Baxter-Jones, 1995; Okazaki, Keller, Fontana, \& Gallagher, 2011) RAEs seem to depend on age and the categories. RAEs were found in the age championship swimmers (11-14) but not in youth championship swimmers (14-17) (Dunman, Morris, Peyrebrune, Warr, \& Nevill, 2005). In some cases RAEs were shown to disappear at adult level (Jimenez \& Pain, 2008; Schorer, Cobley, Busch, Brautigam, \& Baker, 2009) or even reverse. In a recent study, reversal of RAEs was found in U17 FIFA World Cup Competition in football for the Africa nation (Williams, 2010). The reversal of RAEs is when a large portion of players within a team are born in the later part of the selection year, making them relatively younger for their selection year where originally 'normal' RAEs are observed. Bäumler (1998) in his study acknowledged that RAEs in Bundesliga (football) are decreasing as the age increases and additionally suggested that this occurred due to the decrease of the physical advantage of the players born in the first months of the selection year.

Traditional methods of identifying talent seem to play a role. It has been suggested that social agents (coaches, technical directors, and parents) may influence RAEs through selection or initial enrolment (Gutierez Diaz del Campo, Pastor Vicedo, Villora, \& Contreras Jordan, 2010; Hancock et al., 2013). For example, scouts and coaches often look to select the best performers throughout the age groups, often in one off trials. Additionally, many talent identification and development models used to identify and develop talent are based mostly on anthropometric and physiological tests (Vaeyens, Lenoir, Williams, Philippaerts, 
2008). Those tests and emphasis on 'outcome performance' give an advantage to those adolescents who mature earlier than their teammates, because they are likely to be larger, stronger and faster, due to being 'relatively older and/or more mature' (Pearson, Naughton, \& Torode, 2006; Reilly, Banhsbo, Franks, 2000) or have had more opportunities for practice (Côté \& Abernethy, 2007; Wattie, Cobley, \& Baker, 2008). Furthermore, the perception of competence and 'potential' play a significant role in subsequent motivation (Guillet, Sarrazin, Fontaye, \& Brustad, 2006; Harter, 1978). Children that are positively affected by a relative age advantage are likely to be perceived as the most talented in their age group. The Pygmalion effect may increase the relative age advantage of those children if the behaviors of their coaches, parents and teammates continue to encourage and support the initial perception of the children's' abilities (Fernley, 2012; Hancock, Adler, \& Côté, 2013; Rejeski, Darracott, \& Hutslar, 1979). Recently, Hancock et al., (2013) created a theoretical model in an attempt to explain how the Matthew effect (rich get richer; poor get poorer), the Pygmalion and the Galatea effect (self-expectations match outcomes) are manifested by athletes, coaches and parents as they link with the RAEs. Consequently, understanding RAEs is important because the occurrence of RAEs has been linked with drop out and reduced talent pool (Brewer et al., 1995; Delorme, Boiché, \& Raspaud, 2010; Gould \& Maynard, 2009; Helsen, Starkes, \& van Winckel, 1998; Verhulst, 1992).

The occurrence of RAEs is clear in the literature and so are the potential negative effects. However, there is also literature that highlights mediating factors (Wattie, Schorer \& Baker, 2015). For example, popularity of a sport increases the competition for a (potentially) limited number of opportunities. This creates the circumstances that encourage the development of RAEs, particularly where 
'performance outcome' is prioritized (Musch \& Grondin, 2001). Chronological age groupings and competitions from early age are considered to facilitate the development of RAEs as well (Barnsley et al., 1985; Barnsley \& Thompson, 1988; Helsen, van Winckel, \& Williams, 2005; Jimenez \& Pain, 2008; Pierson, Addona, \& Yates, 2014).

Interestingly, several suggestions have been made regarding the reduction or the eradication of RAEs. Firstly, selection criteria solutions have been suggested by researchers. A change in the age category system has been proposed, for example, 15- month or a 21- month category system (Grondin, Deschaies, \& Nault, 1984). Indeed, the opportunity to practice and play with a range of older children and adults appears to be advantageous for development (Côté, Macdonald, Baker, \& Abernethy, 2006). Additionally, Boucher \& Halliwell (1991) proposed the idea of shortening the selection period to 9 months. In a recent study, the dynamic model of the RAE showed that variation of the cutoff date between January $1^{\text {st }}$ and July $1^{\text {st }}$ annually coupled with additional support to the age disadvantaged children led to $96 \% \mathrm{~s}$ (Pierson et al., 2014).

Moreover, technical solutions have been proposed in order to deal with existing RAEs. One of them is to design multiple squads based on multiple standards allowing children to have the opportunity for fair competition (Musch \& Grondin, 2001). Athletes who may be technically at a high level may lack in terms of physical development (Brewer et al., 1995). Therefore, different squads would give the opportunity to these athletes for fair competition. Finally, raising the awareness about the RAEs is a possible approach to the problem because those who are responsible for the organization of a sport should understand the issue of RAEs and how they can affect the development of young athletes (Musch \& Grondin, 2001). 
Importantly, previous studies examining RAEs have used a quantitative approach in order to identify the existence of RAEs. This study is the first exploratory study of RAEs in sports using qualitative methodology. The aim of this study is to qualitatively examine the perceptions of European based 'talent identification and development' (TID) experts in order to investigate the existence, mechanisms and solutions related to RAEs with more depth within a European context.

\section{Methods}

\section{Participants}

The criteria for 'expertise' in this study included the selection of the participants who had worked for more than 10 years professionally in TID roles such as 'elite development' coaches (Ericsson, Krampe, \& Tesch-Romer, 1993) and working in positions with the aim to develop athletes from development to elite level (Martindale, Collins, \& Abraham, 2007). The sample consisted of one chief executive officer of a Scottish premier league football team, one performance director of a UK national governing body, one head of senior coaching and development of a UK national governing body, a youth development coach of an U15 and U16 English premier league football youth academy, a head coach of youth swimming academy in Greece, one taekwondo instructor with a sixth-degree black belt working with developing athletes for more than ten years and finally, a coach of a national division 1 volleyball team in UK. Coaches from different sports were selected in order to give a diverse sample for a variety of sports with a) well established RAEs such as football, b) with mixed findings for RAEs such as swimming and c) with no evidence of RAEs such as taekwondo. There were six 
males and one female coach, five of them working within UK and two in Greece. The average years of experience of the coaches that participated in the study are 17 years with minimum of 10 years and maximum of 25 years.

\section{Design}

A qualitative methodology was used in order to gain an in depth understanding of the phenomenon of RAEs. A semi-structured interview consisted of five main questions was used in an attempt to gain a broad understanding of RAEs in participants' experience. These questions explored the existence of RAEs and how this may change with age; the impact and mechanisms of RAEs; and finally, what is or can be done to reduce negative impact of RAEs. The questions were open-ended and chosen carefully in an attempt to draw truly open-ended responses from the coaches (Patton, 1990). The researcher conducted two pilot interviews with elite level coaches. The feedback from those interviews was used to evaluate and improve the interview guide. Additionally, guidelines proposed by Patton (1990) were also followed in order to guide the interviewer away from biasing the responses of the coaches. This was facilitated by the use of neutral and impartial position when probing participant responses combined with the build of rapport, comfort and open responses (Backstrom \& Hursch-Ceasar, 1981).

\section{Procedures}

The researcher sent a recruiting e-mail along with an information sheet to the coaches that fulfilled the criteria of participating in this study. This outlined the nature of the project and the issues around confidentiality and anonymization of data. Consent form was gained from those participants who volunteered prior to the interviews. The main interview questions were sent to the coaches prior the 
interview in order to enable them familiarize with the type of the questions of the interview. Participants need time to consider their responses and this technique has been suggested to provide more thick and rich data from the participants (Burke \& Miller, 2001). The interviews were chosen to be conducted through telephone or Skype. The interviews lasted approximately 60 minutes and were recorded and transcribed verbatim. So as to ensure the in depth investigation into coaches' perceptions of RAEs, each coach was asked the same sequence of questions, although further clarification and probing was used as required for each coach (Patton, 1990).

\section{Data Analysis}

Analysis was conducted according to the procedures described by Edwards, Kingston, Hardy, \& Gould, (2002) using only inductive analysis. The inductive method was adopted for this study including 1) coding experience 2) inductive inference and 3) similarity processes (Côté, Salmela, Trudel, Baria, \& Russell, 1993). The results were sent back to the coaches in order to ascertain credibility of the findings through stakeholder checks (Patton, 1990). Moreover, reliability checks were carryout in collaboration with other members of the research team (Scanlan, Ravizza, \& Stein, 1989). This procedure included the coding of raw data quotes into raw data themes in $10 \%$ of the interviews, followed by matching all the sub- themes to the general-dimension themes. Two members of the research team conducted the coding independently. They discussed and reviewed their analysis until they reached to $100 \%$ agreement. Finally, according to the grounded theory memos were written in order to capture the thought processes of the researcher and facilitate the best possible analysis of the data (Gucciardi, Gordon, Dimmock, \& Mallett, 2009). 
Results

After the analysis of the data several themes emerged from the inductive analysis which are part of the following section (Williams, 2010). In order to enable the reader gain a better understanding of the context in which the themes emerged from the data quotes are used in the following section of the study.

\section{RAEs and Implications for Effective Practice}

\section{Evidence of relative age effects and reversal of relative age effects.}

RAEs were reported in football, volleyball and cricket while no RAEs were found for taekwondo, swimming and skiing, finding that supports the existing literature. One of the participants gave statistics about the occurrence of RAEs in a football premier league academy and also described the reversal of RAEs for the same team. Interestingly, it seems that despite the fact that elite youth academies in football have a biased selection with the majority of the players born early in the selection year those who actually progress to elite senior/adult level are born late in the selection year. Despite the fact that no RAEs were reported for taekwondo a case of reverse RAE was identified from one of the participants.

We looked at 2000 players to select 40 of them which was the advanced group and from that 40 we signed 18 for the U19 which is a process that happens every year. Out of those 2000 players the $78 \%$ were born in the first four months of the year.

\section{Participant 7}

From my experience in football, English Premier League football academy 2010 had 150 boys of which 26 were born in the second, third and fourth quarter. That meant 124 were born in the first quarter of the year. 10 players were on loan that year; all ten were from the fourth quarter. Those boys on loan were 18, 19 and 20. The academy is up to 18 , so the best players that kept on by English Premier League football academy were all from the fourth quarter. 
My sibling is born on November and is world champion [taekwondo], my sibling is born October and is a European champion [taekwondo], I am born on September and I am world champion [taekwondo].

Participant 4

\section{Advantages and disadvantages of RAEs.}

Physical and mental advantages of being relatively older. The findings of this study supports that more maturely developed children have physical and mental advantages that can facilitate RAEs. Those differences are more likely to occur during puberty because of the great maturation differences during these periods. Especially in young ages a few months difference could create major physical and mental differences which can cause RAEs. More mature young athletes are likely to be taller and heavier which increase their chances of being picked up for a team. Consequently, the physical and mental advantages of relatively older athletes can create RAEs especially in strength-related sports. Furthermore, almost a year of additional training and playing time might be the cause of RAEs amongst youth teams since sport specific abilities can be rapidly improved especially in young ages.

I would say between the ages of 13 to 16 [RAEs are likely to occur]. I would say just before high peak velocity with boys. Girls maybe a little bit earlier. The growth pace of these young children is enormous.

Participant 6

I believe that mental and physical skills [developmental advantages] play a significant role in developing this difference [RAEs] between the children.

Participant 3

I was playing at the national volleyball team under 12 and I believe that the most important reason for that was because I was born on February which gave me the opportunity to have one year more of training.

Participant 3

URL: http://mc.manuscriptcentral.com/rjsp 


\section{RAEs facilitate skewed learning opportunities particularly when there is a} 'win focus'.

Athletes who have this advantage are likely to be picked for their teams especially when teams focus on winning instead of long-term development. Therefore, the extra playing time plus the advanced coaching or more focused coaching can enhance their initial advantage which essentially facilitate and exacerbate the RAEs impact.

Always players born as much as possible closer to the cut-off date receive more attention and will have the advantage of improving due to this attention that they get from the coaches. Therefore it will always be unfair for those who are born later in the selection year because they will not have the same opportunities.

\section{Participant 3}

A number of participants highlighted that the priority of the coaches or scouts is crucial. For example, coaches or scouts who are intentionally or unintentionally selecting, and providing opportunities and attention only to the 'best performers' are likely to be reinforcing RAEs and missing young players with potential who may be relatively younger. Physical advantages in young ages do not necessarily mean that technical aspects of an athlete are higher in comparison to other teammates. However, taking into account the additional playing time for those 'advantaged' youngsters and the attention from the coaches their initial physical advantages leads to advantages in others aspects of the sport. Long-term development instead of winning focus was highlighted from the participants as a necessary shift towards the eradication of RAEs. A prerequisite for this to happen is the education of coaches 
and scouts regarding RAEs in youth sports and in general the fundamentals of talent identification and development.

I know a lot of coaches that because they want to win they will choose the child who is stronger who is quicker than a child who may show some talent but is a little bit smaller.

Participant 6

Each club has scouts and the scouts go out and the scouts pick the players. The scouts have very little education; there is no qualification to scouts in talent recruitment in football. They go out and often they look to the player that has the biggest impact in the game. Therefore, to an uneducated eye those are the ones that are the best players.

Participant 7

\section{RAEs provide useful challenge for 'younger' athletes who 'get in to the} system'.

Through the interviews it was identified that relatively younger and smaller players (who get into the system) face numerous additional challenges through the development process that can facilitate their development and mental toughness in the long term. One of participants stated that those athletes are more likely to progress because of the challenging environment. More specifically, he described that being less mature or less developed in comparison to other athletes (opponents and teammates) may affect positively the personal development of an athlete. This was highlighted in the case of the English Premier League academy in which from all the academy players only those born in the first months of the selection actually made it to the senior level gaining a contract with their team. Being less mature or 'smaller' forces an athlete to be creative, solve problems and be perseverant in order to deal with adversities at all times. This process is possible to develop the psychological characteristics that have been identified to be essential for elite level. As such, incorporating challenge and psychological skills development in a more 
wide spread systematic way is likely to yield advantages for all athletes as opposed to leaving it as a 'consequence' of RAEs.

If you are a smaller player you have to be a problem solver, you are also suffering because you are not getting success all the time. Therefore, you have to deal with adversity as well and all of them are really important traits for a top athlete later on. So imagine you are a problem solver, you deal with diversity and you have unbelievable perseverance that's why you stayed in the program this long because other kids that were small just dropped out. So if you do stick with them and you have strong will as a coach and you encourage them the results can be enormous.

Participant 7

\section{Eradication of RAEs attributed to controllable factors.}

\section{Sport structure categories.}

Where coaches reported a lack of RAEs (swimming, taekwondo and skiing), it was attributed to the structure within the respect sports. The examples in this study show that extended age categories ( 2 years), weight categories and a skills points system (e.g., skiing FIS points) help to eradicate RAEs. However, in the literature it has been identified that the existence of RAEs in swimming depend on the age categories and it is present in some of them. Weight categories in taekwondo and other sports eradicate RAEs because the division criteria are based on weight which ensures fair competition between athletes with similar weight. In alpine skiing FIS points in combination with race results based on month of birth enabled the reduction of RAEs.

No, I don't believe that those effects exist in swimming because age categories are divided every two years.

\section{Participant 1}

I believe that the birth dates has no influence on athletes because of the structure of the [weight] categories in taekwondo. 
We have an alpine selection in alpine skiing based on race results and FIS points. There is a quite nice assessment based on race performance results. They happen in 16,16 and a half, 17, 17 and a half. So we are able to plot a boy or girl results based on the month of birth against the month of birth of the top ten best performers in the main Olympic podium of that same year of birth, or month. So down to the month for Alpine.

Participant 2

In line with this, different division criteria were suggested by the coaches and more specifically division by size or skills. These suggestions would give the opportunity to youngsters to compete with similarly developed athletes in terms of maturation and skills. In sports that strength and size are important dividing teams based on size could offer fair competition for young athletes by creating a challenging environment for the more mature athletes and allowing space for the late developers to participate and get playing time. Regarding sports that strength and size are not substantial training and competing with teammates and opponents within a similar range of skills can be really helpful for the development of athletes and it can be achieved by dividing the athletes in groups based on their skills.

The groups of athletes can be divided not by chronological age but by size especially in sports like volleyball and basketball.

Participant 3

Your skills profile will decide in which group you will get trained or coached.

Participant 2

Moreover, a variety of division strategies were proposed: division in 4 quarters, division every 6 months, 2 years age bands). Shorter period division may eliminate maturation differences while age bands have the potential to allow late developers to keep up and give the opportunity to quick developers to progress to the next age band. 
Another strategy that I have seen is to divide the year in four quarters like English Premier Football Club does and then train and coach the players based on the four quarters rather than based on one year group.

Participant 2

Divide a selection year in two parts, every 6 months instead of 12 could be another solution.

Participant 3

I would suggest age bands. For example if there are $9 \mathrm{~s}$ and $10 \mathrm{~s}$ you would have 9 years old and 10 years old playing together which mean that if you are 9 years old you will have two years playing in that particular age band so if you are a late developer you will have two years in this age band to hopefully catch up. Any kids who are quick developers they can move from one age band to the next age band.

\section{Participant 5}

\section{Long term priority: focus on skills not results.}

The participants suggested that a focus on skills (physical and mental) instead of outcome results would contribute to the eradication of RAEs. However, this relies on the sport prioritizing long-term development over age group success. One of the participants suggested that mental skills are a key characteristic that help athletes during their athletic career and underpins 'realizing potential'. Developing the mental side of athletes or in other words developing an athlete as a person is a crucial element for their successful long-term development.

On other sports we were able to eradicate it because we are looking at skills. We are not looking at the ability to win competitions...I would say more mental skills because mental skills are what we get people to demonstrate [because mental skills underpin long term development].

Participant 2

\section{Delay selection \& provide for late developers.}

It was highlighted that the ignorance of 'late developers' may strengthen RAEs. By only providing early windows of opportunity for selection, athletes who may have great potential may be missed if they are 'young for their year' or not the 
'best performers' at early stages. Taking into consideration that some characteristics need several years to emerge late developers should not be neglected because they may reach their best potential later than their teammates. Therefore, those athletes need to be supported and be given the opportunity to participate and compete.

It is extremely bad practice for a development environment or a development pathway not to acknowledge late developers because I think there is a possibility you close the door on a number of individuals who could participate in a sport because of this negative effect of not being chosen and just been ignored because they haven't developed in the same level.

Participant 6

One of the participants emphasized the importance of the timing of the selection process. Early selection creates 'rejection' and narrows the potential talent base. By giving athletes time and allowing them to develop it is more likely to avoid drop out and in the same allow space for late developers. Reducing the talent pool reduces subsequently the chances of producing great elite athletes. In addition to this, performances at youth competitions are not a guarantee for later success at senior level. Rejecting a youngster may drive him/her to disengagement from sport which is a negative outcome for both the athletes and the society as a whole.

I think we need to take more kids and I think that we need to make the selection later on. I think we select the players far too early and players feel rejected far too early.

Participant 7

\section{The need for education.}

Participants suggested that a helpful step would be to educate coaches/scouts and any other relevant parties where necessary with regards to RAEs and also what 'talent' is within a long term perspective. For example, what are the possible effect of birthdates and the different levels of maturation? What are the pros and cons of different category strategies and/or later selection processes? What are the priorities 
for the coaches/scouts/clubs? Education of coaches and scouts involved in youth age groups is of paramount importance because they have a substantial impact on the future of the young athletes. Thus, coaches and scouts need to be educated not only regarding RAEs but also "what talent is"' as one of the participants described. It is necessary to be clear for the scouts/ coaches which are the elements they should look for and which are the skills they should focus on developing.

Coaches need to be educated on the effect of age and the effect of children developing at different levels, at different rate of maturity and understanding that they could have kids who are beyond their years or under their years in terms of development and how to deal with that and the potential effect.

Participant 6

We need to improve the education of scouts. I think the education of scouts is of paramount importance. They are the people that are going out and bring the players to the clubs and they have to know what talent is.

Participant 7

\section{Discussion}

The findings of this study are in line with previous literature showing that maturation and physical differences may create RAEs (Baxter-Jones, 1995; Maffulli et al., 1994) especially in strength related sports such as football (Jimenez \& Pain, 2008; van den Honert, 2012), volleyball (Baxter-Jones, 1995; Okazaki et al., 2011), and cricket (O’ Donoghue et al., 2004). Additionally, no RAEs were described by the participants for swimming taekwondo and skiing. This study supported earlier research which has confirmed that certain division strategies have eradicated RAEs. This finding was attributed to the different division strategies used in those sports. For instance, no RAEs were identified amongst Olympic taekwondo athletes (Albuquerque, Lage, \& Teoldo da Costa, 2012); finding which is in line with 
research showed that weight categories prevented the development of RAEs (Delorme, 2014). Regarding skiing, one of the participants suggested that FIS points are able to eradicate RAEs, although in a recent study RAEs were found in skiing for both males and females (Baker, Janning, Wong, Cobley \& Schorer, 2014). In addition, this research supports previous work that highlights increased opportunities and attention is often given to relatively older athletes because they are better performers (Musch \& Grondin, 2001; Wilson, Cushion, \& Stephens, 2006). For example, in a recent study with hockey players attending a selection camp it was found that the players selected for the final team were taller, heavier and the majority of them were born between January to June (Sherar, Baxter-Jones, Faulkner, \& Russell, 2007), despite the fact that the coaches were aware that their future potential in terms of physical development were the same. Likewise, Till et al., (2010) showed that anthropometric and physical variables are not a predictor of performance at the elite level. This finding reinforces the fact that late developers should not be neglected at early stages of the development pathway. It has been identified that systems should be in place in order to help athletes with potential that may have been overlooked by an early selection (Abbott, Button, Pepping, \& Collins, 2005; Martindale et al., 2007). It should also be taken into consideration that some characteristics of talent may need several years to emerge (Simonton, 1999).

Moreover, this study gave evidence of reversal of RAEs at an elite level football academy and in taekwondo. Reversal of RAEs is the appearance of a large portion of players (within a team) born towards the last part of the selection year, making them relatively younger for their selection year and then reach the elite level. Reversal of RAEs has been described in the literature in football (Bäumler, 1998; Williams, 2010) and shooting sports (Delorme \& Raspaud, 2009). Relatively 
younger athletes can be facilitated by the continuous challenges and develop the toolbox of essential skills that is required for competing at elite senior level. Interestingly, this is one explanation that has been given for the development of reversal of RAEs, whereby those younger athletes who do 'make it into the system' have to overcome the challenge of performing against older, more mature opponents on a regular basis (Collins \& MacNamara, 2012). Therefore, implementing 'structured' challenge along with psychological skills development in a systematic way is likely to be beneficial for all athletes (Alfermann \& Stambulova, 2007; Bull, Shambrrok, James, \& Brooks, 2005; Collins \& MacNamara, 2012; Gould, Dieffenbach, \& Moffett, 2002; MacNamara \& Collins, 2010; MacNamara, Button, \& Collins, 2010). Additionally, one of the participants suggested that mental skills are a key characteristic that help athletes progress during their athletic career (MacNamara \& Collins, 2010; MacNamara et al., 2010) in the long- term (Henriksen, 2010; Martindale et al., 2007). Therefore, mental skills should be identified, promoted and developed throughout the athletic career.

Similarly to previous research participants suggested a shorter period division of 9 months (Boucher \& Halliwell, 1991) in order to reduce maturation differences. They also proposed age bands of 15 to 21 months (Grondin et al., 1984) in an attempt to give time to late developers to flourish and allow to the progressed athletes move to next age band. Another division strategy suggested in this study is division by skills which has been suggested in the literature (Baxter-Jones, 1985). However, dividing young athletes according to their skills could increase the injury risk during a collision (Wattie, 2013). Côté and his colleagues (2006) suggested that the environment of smaller cities is conducive to unstructured play between different 
ages and allow experimentation which is possible to facilitate the development of athletes towards elite level.

Furthermore, the majority of the coaches emphasized on the need for education and long-term priority. They suggested that education is essential for scouts and coaches since in some cases they perceive physical maturity as talent (Sherar et al., 2007; Till et al., 2011). Moreover, the participants proposed that there is a need to focus on developing skills instead of winning. Essentially, prioritization of long term development instead of transient results was highlighted by the participants; suggestions that fit well with guidelines for effective talent development environments (Martindale et al., 2007). However, there is pressure from coaches and teams for results in young ages and in general success at youth age groups. Consequently, the philosophy of the current system as a whole needs to be aligned with its aims (Pankhurst \& Collins, 2013).

\section{Conclusion}

This study explored the existence, mechanisms and solutions that may exist with regards to RAEs within a European context. There were mixed results with regards to its existence, with some evidence for reversal of RAEs. The participants gave some evidence for reversal of RAEs. In those sports where RAEs did not exist, it was attributed to controllable factors such as the structure of the categories used to group the athletes (e.g., expanded age, weight, or skill categories) and/or prioritizing long term development. Furthermore, it seemed clear that the need to understand the nature of 'talent' and its development within a long term perspective is needed 
(Henriksen, 2010; MacNamara \& Collins, 2010; MacNamara et al., 2010; Martindale et al., 2007). In short, when a 'win or outcome focus' is paramount at developmental ages, those with maturation/performance advantages inevitably get prioritized, at the expense of other relatively younger peers. Interestingly, it was reported that those 'relatively younger' athletes who were able to 'access the system' benefited from the developmental challenge of having to train and compete with older and/or bigger peers on a regular basis. However, as previous research has highlighted, 'challenge' can facilitate the development of athletes in their best potential (Bull et al., 2005; Gould et al., 2002). Moreover, a recent study suggested that 'structured challenge' can be implemented more systematically to aid development in all athletes, and doesn't have to be reserved as an ad hoc consequence of RAEs (Collins \& MacNamara, 2012). Leading on from this, it appears that the priorities and planning of coaches, scouts, National Governing Bodies and clubs needs to revolve around long term development if the RAE and related negative consequences are to be eradicated.

It is important to highlight both limitations and strengths of this exploratory study. Firstly, the number of coaches involved in this study was small $(\mathrm{N}=7)$. However, to provide some context to this number, the selection of the participants was made carefully and based on specific criteria in an attempt to access opinions and experiences of those we termed applied 'experts' within the field of TID. Even so, more in depth investigation within in specific sports, including investigating the experiences of other relevant parties such as parents and athletes would add value to this area of research.

This study gave further insight to the issue of RAEs in sports. However, there is a need of further research of this phenomenon, particularly in relation to understanding 
the mechanisms of the RAE and examining the efficacy of different strategies in eradicating it. Further examination will allow us to design and implicate potential solutions in practice. The RAE is an issue that needs to be addressed because it is vital for young children to have equal opportunities for participation and development in their best potential within sport.

\section{References}

Abbott, A., Button, C., Pepping, G. J., \& Collins, D. (2005). Unnatural selection: talent identification and development in sport. Nonlinear Dynamics and Psychology of Life Sciences, 9(1), 61-88.

Albuquererque, M.R., Lage, G.M., Teoldo da Costa, V. (2012). Relative age effect in Olympic taekwondo athletes. Perceptual and Motor Skills, 114(2), 461-468.

Alfermann, D. \& Stambulova, N. (2007). Career transitions and career termination. In R. Eklund, \& G. Tenenbaum (Eds.), Handbook of Sport Psychology ((edited by Eklund R. \& Tenenbaum G.) $3^{\text {rd }}$ ed.), pp. 712-736, New York: Wiley.

Backstrom, C. H., \& Hursch-Ceasar, G. (1981). Conducting Interviews: Survey Research (2nd ed.). New York: John Wiley and Sons.

Barnsley, R. H., \& Thompson, A. H. (1988). Birthdate and success in minor hockey: The key to the NHL. Canadian Journal of Behavioural Science, 20, 167-176.

Barnsley, R. H., Thompson, A. H., \& Barnsley, P. E. (1985). Hockey success and birthdate: The RAE. Canadian Association for Health, Physical Education, and Recreation, 51, 23-28. 
Bäumler, G. (1998). Der Realtivalterseffekt bei Fußballspielern und seine Wechselwirkung mit dem Lebensalter \{Relative age effect in football players and its interactions with chronological age\}. In G. Bäumler, \& G. Bauer G. (Eds.), ). Sportwissenschaft rund um den Fußball (, pp. 109-115). Hamburg: Czwalina.

Baxter-Jones, A. (1995). Growth and development of young athletes. Should competition levels be age related? Sports Medicine, 20, 59-64.

Boucher, J., \& Halliwell, W. (1991). The Novem System: a practical solution to age grouping. Canadian Association for Health, Physical Education and Recreation, $57(1), 16-20$.

Boucher, J., \& Mutimer, B. (1994). The relative age phenomenon in sport: A replication and extension with ice-hockey players. Research Quarterly for Exercise and Sport, 65, 377-381.

Brewer, J., Balsom, P., \& Davis, J. (1995). Seasonal birth distribution amongst European soccer players. Sports Exercise and Injury, 1, 154-157.

Bull, S.J., Shambrook, C.J., James, W., \& Brooks, W.J. (2005). Towards an understanding of mental toughness in elite English cricketers. Journal of applied sport psychology, 17, 209-227.

Burke, L., \& Miller, M. (2001). Phone Interviewing as a Means of Data Collection: Lessons Learned and Practical Recommendations. Forum Qualitative Sozialforschung / Forum: Qualitative Social Research, 2(2).

Cobley, S., Baker, J., Wattie, N. \& McKenna, J. (2009a). How pervasive are relative age effects in secondary school education? Journal of Educational Psychology, 101, $520-528$. 
Cobley, S., Baker, J., Wattie, N., \& McKenna, J. (2009b). Annual Age-Grouping and Athlete Development. A Meta-Analytical Review of Relative Age Effects in Sport. Sports Medicine, 39(3), 235-256.

Collins, D., \& MacNamara, Á. (2012). The Rocky Road to the Top: Why Talent Needs Trauma. Sports Medicine, 42(11), 907-914.

Côté, J., Baker, J., \& Abernethy, B. (2007). Practice and Play in the Development of Sport Expertise. In G. Tenenbaum, \& R.C. Eklund (Eds.) Handbook of Sport Psychology ((edited by Tenenbaum, G. and Eklund, R.C.) $3^{\text {rd }}$ ed.ition), pp. 184-202. New Jersey: Wiley.

Côté, J., Macdonald, D. J., Baker J. \& Abernethy B. (2006): When "where" is more important than "when": Birthplace and birthdate effects on the achievement of sporting expertise, Journal of Sports Sciences, 24(10), 1065-1073.

Côté, J., Salmela, J., Trudel, P., Baria, A., \& Russell, S. (1993). Organising and interpreting unstructured qualitative data. The Sport Psychologist, 7, 127-137.

Delorme N, Raspaud M. (2009). Influence of the relative age effect on the dropout of sports activities. Proceedings of the 13th Annual Congress of the ECSS: Estoril: European College of Sport Science, pp. 72-73.

Delorme N. (2014). Do weight categories prevent athletes from relative age effect? Journal of Sports Sciences, 32(1), 16-21,

Delorme, N., Boiché, J., \& Raspaud M. (2010) Relative age and dropout in French male soccer. Journal of Sports Sciences, 28(7), 717-722. 
Dunman, N., Morris, J.G., Peyrebrune, M., Warr, C.R.,, \& Nevill, M.E. (2005). The relative age effect in elite junior swimmers. Journals of Sports sciences, 23, 11-12.

Edgar, S., \& O’ Donoghue, P. (2005). Season of birth distribution of elite tennis players. Journal of Sports Science, 23(10), 1013-1020.

Edwards, T., Kingston, K., Hardy, L., \& Gould, D. (2002). A qualitative analysis of catastrophic performances and the associated thoughts, feelings, and emotions. The Sport Psychologist, 16, 1-19.

Ericsson, K.A., Krampe, R.T., \& Tesch-Romer, C. (1993). The role of deliberate practice in the acquisition of expert performance. Psychological Review, 100(3), 363-406.

Fernley, P.D. (2012). Relative age effects in Australian junior rugby union. Master's thesis, School of Leisure, Sport and Tourism University of Technology, Sydney.

Gould, D., Dieffenbach, K., \& Moffett, A. (2002). Psychological characteristics and their development in Olympic champions. Journal of applied sport psychology, 14, 172-204.

Gould, D., Maynard, I. (2009). Psychological preparation for the Olympic Games. Journal of Sports Sciences, 27(13), 1393- 1408.

Grondin, S., \& Koren, S. (2000). The relative age effect in professional baseball: A look at the history of Major League Baseball and at current status in Japan. Avante, 6, 64-74.

Grondin, S., Deschaies, P., \& Nault, L. P. (1984). Trimestres de naissance et rendement scolaire. Apprentissage et Socialisation, 16, 169-174. 
Gucciardi, D.F., Gordon, S., Dimmock, J., \& Mallett, C.J. (2009). Understanding the coach's role in the development of mental toughness: perspectives of elite Australian football coaches. Journals of Sports Sciences, 27(13), 1483- 1496.

Guillet, E., Sarrazin, P., Fontayne, P., \& Brustad, R.J. (2006). Understanding female sport attrition in a stereotypical male sport within the framework of Eccles' expectancy-value model. Psychology of Women Quarterly, 30(4), 358-368.

Gutierrez Diaz del Campo, D., Pastor Vicedo, J. C., Gonzalez Villora, S., \& Contreras Jordan, O. R. (2010). The relative age effect in youth soccer players from Spain. Journal of Sports Science \& Medicine, 9, 190-198.

Hancock, D.J., Adler, A.L., Côté, J. (2013). A proposed theoretical model to explain relative age effects in sport. European Journal of Sport Science, 13(6), 630-637.

Harter, S. (1978). Effectance motivation reconsidered: Toward a developmental model. Human Development, 21, 34-64.

Helsen, W. F., Starkes, J. L., \& van Winckel, J. (1998). The influence of relative age on success and dropout in male soccer players. American Journal of Human Biology, 10, 791-798.

Helsen, W. F., van Winckel, J., \& Williams, A. M. (2005). The relative age effect in youth soccer across Europe. Journal of Sports Sciences, 23(6), 629-636.

Henriksen, K. (2010). The ecology of talent development in sport: a multiple case study of successful athletic talent development environments in Scandinavia. $\mathrm{PhD}$ Thesis, University of Southern Denmark. 
Jiménez, P. I., \& Pain, M. T. G. (2008). Relative age effect in Spanish association football: Its extent and implications for wasted potential. Journal of Sports Sciences, 26, 995-1003.

MacNamara, Á, Collins, D. (2010). The role of psychological chracteristics in managing the transition to university. Psychology of Sport and Exercise, 11(5), $353-$ 362.

MacNamara,, Á.,., Button, A., \& Collins, D. (2010). The Role of Psychological Characteristics in Facilitating the Pathway to Elite Performance Part 2: Examining Environmental and Stage-Related Differences in Skills and Behaviors. The Sport Psychologist, 24, 74-96.

Maffulli, N., King, J.B., \& Helms, P. (1994). Training in élite young athletes (the Training of Young Athletes (TOYA) Study): injuries, flexibility and isometric strength. British Journal of Sports Medicine, 28, 123-126.

Martindale, R., Collins, D., \& and Abraham, A. (2007). Effective Talent Development: The Elite Coach Perspective in UK Sport'. Journal of Applied Sport Psychology, 19(2), 187 -- 206.

Musch, J., \& Grondin, S. (2001). Unequal Competition as an impediment to personal development: A review of the relative age effect in sport. Developmental Review, 21(2), $147-167$.

Musch, J., \& Hay, R. (1999). The relative age effect in soccer: Cross-cultural evidence for a systematic discrimination against children born late in the competition year. Sociology of Sport Journal, 16, 54-64. 
O’ Donoghue, P., Edgar, S., \& McLaughlin, E., (2004). Season of birth buas in elite cricket and netball. Journal of Sports Science, 22, 256-257.

Okazaki, F.H.A., Keller, B., Fontana, F.E., Gallagher, J.D. (2011). The relative age effect among female Brazilian youth volleyball players. Research Quarterly for exercise and sport, 82(1), 135- 139.

Pankhurst, A., Collins, D. (2013). Talent Identification and Development: The Need for Coherence Between Research, System, and Process'. Quest, 65(1), 83-97.

Patton, M. (1990). Qualitative evaluation methods ( $2^{\text {nd }}$ ed.ition). Beverly Hills, CA: Sage.

Pearson, D. T., Naughton, G. A., \& Torode, M. (2006). Predictability of physiological testing and the role of maturation in talent identification for adolescent team sports. Journal of Science and Medicine in Sport, 9, 277-287.

Pierson, K., Addona V. \& Yates P. (2014) A behavioural dynamic model of the relative age effect. Journal of Sports Sciences, 32(8), 776-784.

Reilly, T., Bangsbo, J., \& Franks, A. (2000). Anthropometric and physiological predispositions for elite soccer. Journal of Sports Sciences, 18(9), 669-683.

Rejeski, W., Darracott, C., \& Hutslar, S. (1979). Pygmalion in youth sport: A field study. Journal of Sport Psychology, 1, 311-319.

Scanlan, T. K., Ravizza, K., \& Stein, G. L. (1989). An in-depth study of former elite figure skaters: 1. Introduction to the project. Journal of Sport and Exercise Psychology, 11, 54-64.

Schorer, J., Cobley, S., Busch, D., Brautigam, H., \& Baker, J. (2009). Influences of competition level, gender, player nationality, career stage and playing position on 
relative age effects. Scandinavian Journal of Medicine and Science in Sports, 19(5), 720-730.

Sherar, L. B., Baxter-Jones, A. D. G., Faulkner, R. A., \& Russell, K. W. (2007). Do physical maturity and birth date predict talent in male youth ice hockey players? Journal of Sports Sciences, 25, 879-886.

Simonton, D. (1999). Talent and its development: an emergenic and epigenetic model. Psychological Review, 106, 435-57.

Till, K., Cobley, S., O’Hara, J., Brightmore, A., Cooke, C., \& Chapman, C. (2011). Using anthropometric and performance characteristic to predict selection in junior UK Rugby League players. Journal of Science and Medicine in Sport, 14, 264-269.

Till, K., Cobley, S., Wattie, N., O'Hara, H., Cooke, C., \& Chapman, C. (2010). The prevalence, influential factors and mechanisms of relative age effects in UK Rugby League. Scandinavian Journal of Medicine and Science in Sports, 20(2), 320-329.

Vaeyens, R., Lenoir, M., Williams, A. M., \& Philippaerts, R. M. (2008). Talent identification and development programmes in sport: current models and future directions. Sports Medicine, 38(9), 703-714.

Verhulst, J. (1992). Seasonal birth distribution of West European soccer players: A possible explanation. Medical Hypotheses, 38, 346-348.

vvan den Honert, R. (2012). Evidence of the relative age effect in football in Australia. Journal of Sports Sciences, 30(13), 1365- 1374.

Wattie, N., Cobley, S., \& Baker, J. (2008). Towards a unified understanding of relative age effects. Journal of Sports Sciences, 26(13), 1403-1409. 
Wattie, N., Schorer, J., \& Baker, J. (2015). The relative age effect in sport: A developmental systems model. Sports Medicine, 45, 83-94.

Williams, J.H. (2010). Relative age effect in youth soccer: analysis of the FIFA U17 World Cup competition. Scandinavian Journal of Medicine and Science in Sports, 20, 502-508.

Wilson, M.A., Cushion, C. J., \& Stephens, D. E. (2006). Put me in coach... I'm better than you think I am! : Coaches' perceptions of their expectations in youth sport. International Journal of Sports Science \& Coaching, 1(2), 149-161.

Côté, J., Macdonald, D.J., Baker, J., \& Abernethy, B. (2006) When "where” is more important than "when": Birthplace and birthdate effects on the achievement of sporting expertise. Journal of Sports Sciences, 24(10), 1065-1073. 